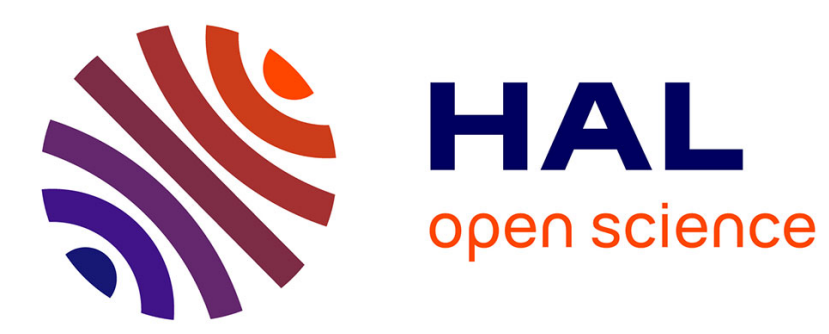

\title{
Multiarms Multiports Externally Fed Spiral Antenna
}

Karim Louertani, Régis Guinvarc'H, Nicolas Ribière-Tharaud, Marc Hélier

\section{To cite this version:}

Karim Louertani, Régis Guinvarc'H, Nicolas Ribière-Tharaud, Marc Hélier. Multiarms Multiports Externally Fed Spiral Antenna. IEEE Antennas and Wireless Propagation Letters, 2012, 11, pp.236239. 10.1109/LAWP.2012.2188372 . hal-00693316

\section{HAL Id: hal-00693316 https: / hal.sorbonne-universite.fr/hal-00693316}

Submitted on 30 Jul 2021

HAL is a multi-disciplinary open access archive for the deposit and dissemination of scientific research documents, whether they are published or not. The documents may come from teaching and research institutions in France or abroad, or from public or private research centers.
L'archive ouverte pluridisciplinaire HAL, est destinée au dépôt et à la diffusion de documents scientifiques de niveau recherche, publiés ou non, émanant des établissements d'enseignement et de recherche français ou étrangers, des laboratoires publics ou privés.

\section{(c)(1)}

Distributed under a Creative Commons Attribution| 4.0 International License 


\title{
Multiarms Multiports Externally Fed Spiral Antenna
}

\author{
Karim Louertani, Régis Guinvarc'h, Member, IEEE, Nicolas Ribière-Tharaud, and Marc Hélier
}

\begin{abstract}
This letter deals with an externally fed spiral antenna. This design is a slot antenna that exhibits a behavior similar to that of the center-fed Archimedean spiral antenna with an improvement in terms of polarization. The antenna radiates a circular polarization over a wide frequency band within a wide angular range. Moreover, the polarization radiated can be right/left circular or linear vertical/horizontal. A prototype has been manufactured and compared to the modeled antenna. Good agreement is shown between measurement and simulation results.
\end{abstract}

Index Terms - Circular polarization, externally fed, spiral antenna, wideband.

\section{INTRODUCTION}

$\mathbf{S}$ PIRAL antennas [1], [2] are well known to be suitable for applications that require a wide frequency band and circular polarization (right-hand and/or left-hand circular polarization). Usually, they are center-fed, and a balanced signal excites the first mode. In this case, the current on the antenna is symmetric with respect to the center over the entire surface. However, in some configurations, the center is not accessible. A solution is to shift the feeding from the center to the outermost arms. Studies have been done in this way in order to control the polarization at the cost of the quality of the far-field pattern [3]. Some designs require the use of resistive loads that affect the efficiency. A three-arm spiral antenna with coplanar feeding solution has been proposed in [4], and a two-arm with a outer feed in [5]. In both cases, the lower frequency is around twice that of the theoretical lower frequency limit. Moreover, the shape of the far-field pattern is not the same over the frequency range. Good results in terms of bandwidth are obtained in [6], however the radiated polarization is not circular. In order to obtain the same behavior as the classical center-fed spiral, the design has to be fed to keep the symmetry of the current on the antenna. This is achieved by adding other sources with a phase shift. In this letter, an externally fed spiral antenna is studied, and measurements have been done to supplement simulation results.

\section{ANTENNA DESIGN}

The first mode of the spiral antenna is achieved by a balanced feeding. This results in a symmetrical current distribution

K. Louertani was with the Laboratory SONDRA, Supelec, 91192 Gif-surYvette, France. He is now with the L2E, UPMC University Paris 06, 75005 Paris, France (e-mail: karim.louertani@gmail.com).

R. Guinvarc'h is with the Laboratory SONDRA, Supelec, 91192 Gif-surYvette, France.

N. Ribière-Tharaud is with the CEA, DAM, GRAMAT, 46500 Gramat, France.

M. Hélier is with the L2E, UPMC University Paris 06, 75005 Paris, France.

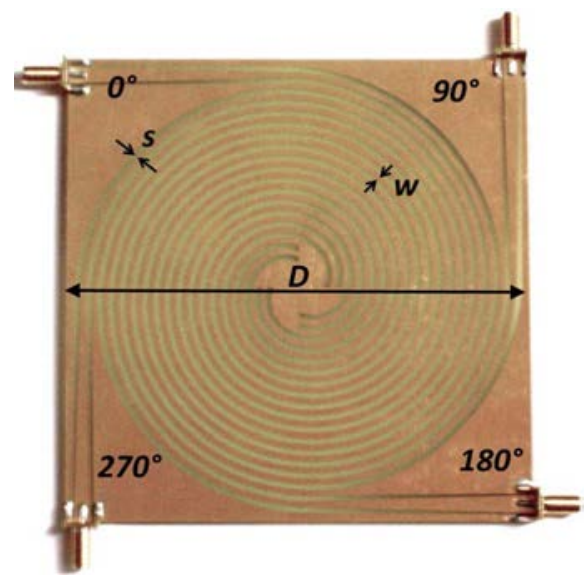

Fig. 1. Built $4 \times 2$-arms spiral antenna.

TABLE I

GEOMETRICAL CHARACTERISTICS

\begin{tabular}{c||c}
\hline \hline Description & Values \\
\hline \hline Diameter $: D$ & $125 \mathrm{~mm}$ \\
\hline Slot width $: w$ & $1.59 \mathrm{~mm}$ \\
\hline Space between slots $: s$ & $1.59 \mathrm{~mm}$ \\
\hline Number of turns & 2 \\
\hline \hline
\end{tabular}

with respect to the antenna center. Since the new antenna has to keep the behavior of a center-fed spiral antenna with an external feeding, the principle of symmetry for the geometry and the current has to be applied [7]. The built antenna shown in Fig. 1 has been modeled with the software CST Microwave Studio. This new design is a slot antenna etched on a copper plate of $13 \times 13 \mathrm{~cm}^{2}$ with a 0.8 -mm FR4 substrate. To achieve this design, a spiral arm is duplicated and sequentially rotated by $90^{\circ}$, $180^{\circ}$, and $270^{\circ}$ with respect to the center of the antenna. This results in a symmetrical design with respect to the center. Each couple of lines starts with a short straight tapered section before being wound in a spiral shape. The geometrical characteristics are provided in Table I.

\section{FeEding CONFIGURATION}

At each feed point, a coplanar waveguide is connected to an SMA connector. Four sources provide thus an unbalanced signal to the antenna, and a phase shift of $90^{\circ}$ is applied between two consecutive sources. Hence, the antenna is fed by four unbalanced signals with a phase shift of $0^{\circ}, 90^{\circ}, 180^{\circ}$, and $270^{\circ}$, respectively [8]. Due to the symmetry of the geometry and the feeding, the current is symmetric on the antenna. This property leads to a symmetrical far-field pattern that is presented further in this letter. The tapered coplanar waveguides are used as a matching transition from the input impedance of the antenna to 


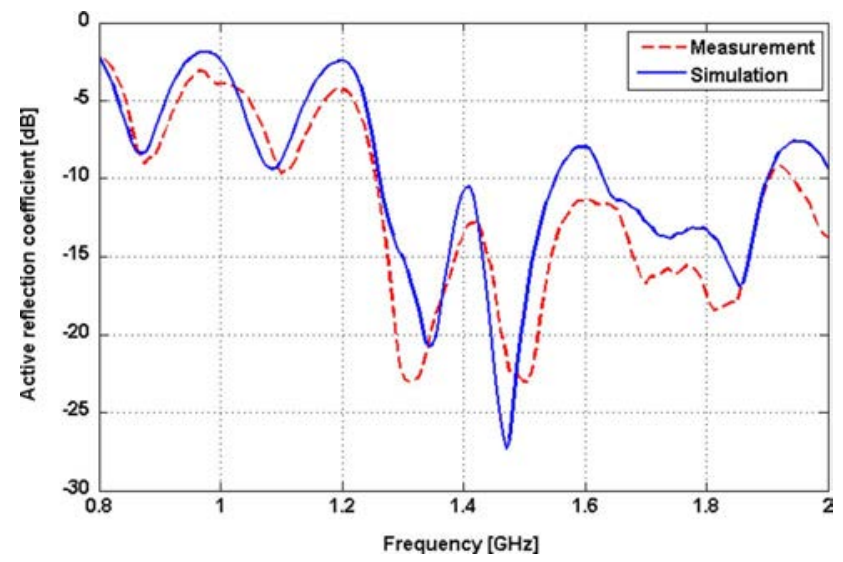

Fig. 2. Measurement: comparison of the measured and simulated active reflection coefficient against frequency for a reference impedance $Z_{c}=50 \Omega$.

$50 \Omega$. In this case, baluns are not needed, and the $4 \times 2$-arms slot antenna could be easily fed by coaxial cables.

\section{RESULTS}

\section{A. Active Reflection Coefficient}

The active reflection coefficient (ARC) of the antenna is the sum of the four ports contribution. In our case, the ARC can be rewritten as

$\mathrm{ARC}=S_{11}+S_{12} \exp \left(\mathrm{j} \frac{\pi}{2}\right)+S_{13} \exp (\mathrm{j} \pi)+S_{14} \exp \left(\mathrm{j} \frac{3 \pi}{2}\right)$.

The measured and simulated ARCs calculated with a reference impedance of $50 \Omega$ are depicted in Fig. 2. The two curves are in good agreement. According to the measurement results, $\mathrm{ARC} \leq-10 \mathrm{~dB}$ is achieved from 1.25 up to $2 \mathrm{GHz}$ (except between 1.9 and $1.94 \mathrm{GHz}$, where $\mathrm{ARC} \leq-9.2 \mathrm{~dB}$ ). The bandwidth could be improved by reducing the reflections in the center of the antenna. A solution could be the use of resistive loads to dissipate the power at the cost of the efficiency [9]. Moreover, the transition slot lines could be further optimized to enhance the matching impedance at the lower frequencies.

\section{B. Polarization}

The performances in terms of polarization are described by the axial ratio (AR) plotted against frequency in Fig. 3 for $\theta=$ $0^{\circ}$ to $40^{\circ}$ in steps of $10^{\circ}$. The AR is defined as the ratio of the major and minor values of the electrical far field. For an $\mathrm{AR}=1$, the radiated polarization is perfectly right-hand circular. Inversely, for an $\mathrm{AR}=-1$, the polarization is perfectly left-hand circular [10]. A good circular polarization is radiated for an $|\mathrm{AR}| \geq 0.7$, which corresponds to a rejection of the cross polarization greater than $15 \mathrm{~dB}$. All the curves are above $0.7 \mathrm{ex}-$ cept for $\theta=30^{\circ}$ at $1.9 \mathrm{GHz}(\mathrm{AR} \geq 0.68)$ and for $\theta=40^{\circ}$. The $4 \times 2$-arms spiral antenna exhibits a perfect circular polarization $(\mathrm{AR}=1)$ at boresight. The purity of the circular polarization decreases when $\theta$ moves away from boresight up to a value comprised between $30^{\circ}$ and $40^{\circ}$. Hence, a good circular polarization

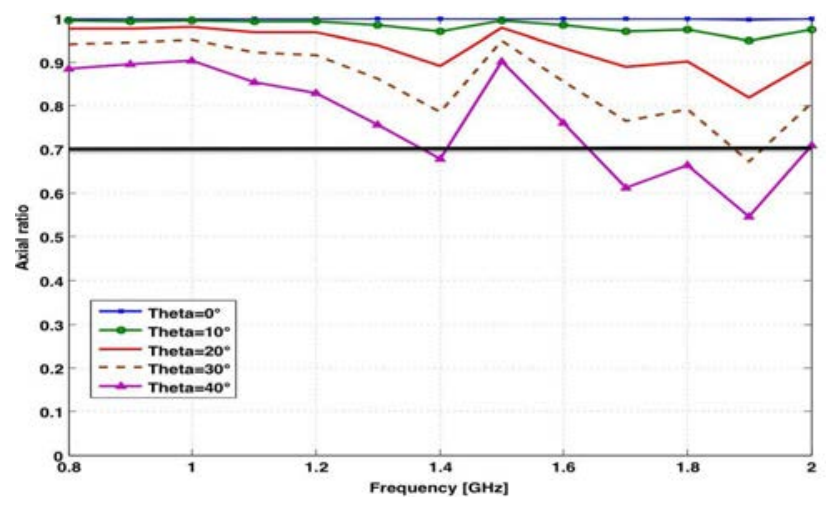

Fig. 3. Simulation: axial ratio against frequency for $\theta=0^{\circ}$ to $40^{\circ}$.

- config 1 - - - config $2 \cdots \cdots$ config $3-$ config $4^{-\cdots}$

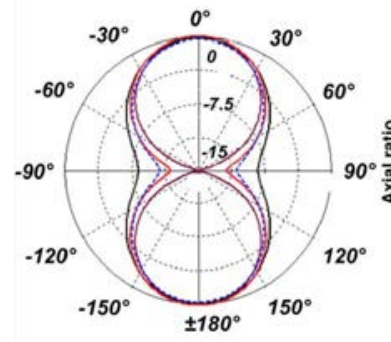

(a)

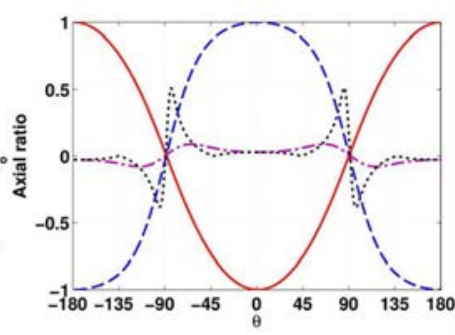

(b)
Fig. 4. Simulation: (a) cuts in elevation of the normalized gain and (b) AR at $1.5 \mathrm{GHz}$.

TABLE II

Phase Shift Configurations at $\theta=0^{\circ}$

\begin{tabular}{|l|c|c|c|c|c|}
\hline & Port 1 & Port 2 & Port 3 & Port 4 & Polarization \\
\hline Configuration 1 & $0^{\circ}$ & $90^{\circ}$ & $180^{\circ}$ & $270^{\circ}$ & LHCP \\
\hline Configuration 2 & $0^{\circ}$ & $270^{\circ}$ & $180^{\circ}$ & $90^{\circ}$ & RHCP \\
\hline Configuration 3 & $0^{\circ}$ & $\mathrm{x}$ & $180^{\circ}$ & $\mathrm{x}$ & $\mathrm{H}$ \\
\hline Configuration 4 & $\mathrm{x}$ & $0^{\circ}$ & $\mathrm{x}$ & $180^{\circ}$ & $\mathrm{V}$ \\
\hline
\end{tabular}

(x: port matched to $50 \Omega$ )

is radiated within $\pm 30^{\circ}$ at boresight, i.e., $60^{\circ}$. As a result, most of the power is radiated with a circular polarization.

According to the phase shift and the voltage applied to the ports, different polarizations are radiated. For each case, a cut in elevation of the normalized gain is plotted in Fig. 4 with the associated axial ratio. All configurations are summarized in Table II. In all cases, the radiated patterns are the same, as shown in Fig. 4(a). In the two first configurations, all ports are fed with the same magnitude and a phase shift of $0^{\circ}, 90^{\circ}, 180^{\circ}$, and $270^{\circ}$ or reversed. This leads to the radiation of a left- or right-hand circular polarization as described by the curves of configurations 1 and 2. For the two last configurations, only two ports are fed with a phase shift of $180^{\circ}$. The others ports are matched to $50 \Omega$ and are designated by a cross in Table II. When ports 1 and 3 are fed, a horizontal linear polarization is radiated at $\theta=0^{\circ}$. However, when ports 2 and 4 are fed, the radiated polarization is vertical linear. In these cases, the AR is close to 0 at $\theta=0^{\circ}$. This antenna could be used as a multifunction antenna with a tunable polarization. 


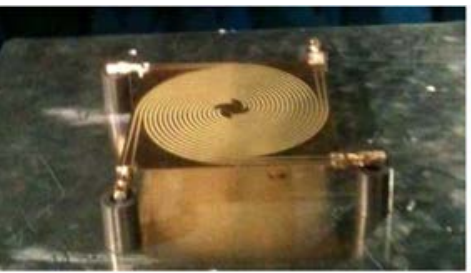

(a)

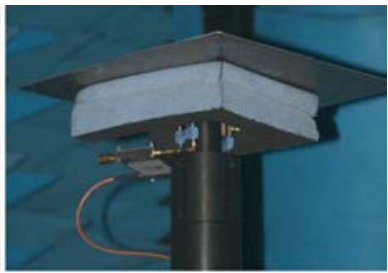

(b)
Fig. 5. Measurement: (a) $4 \times 2$-arms spiral antenna at $3 \mathrm{~cm}$ above a ground plane and (b) the antenna with the feeding circuitry.

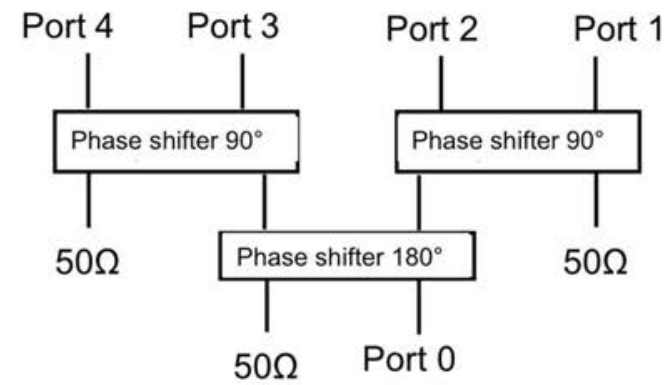

(a)

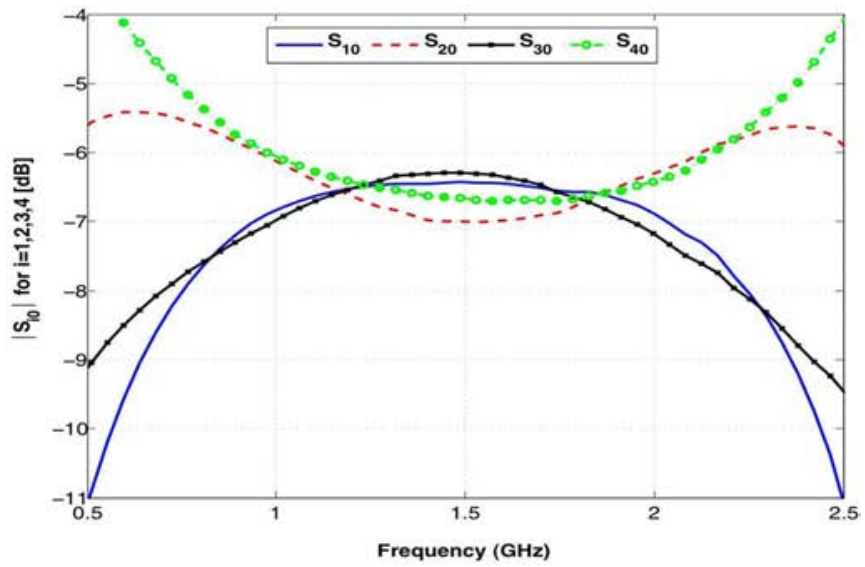

(b)

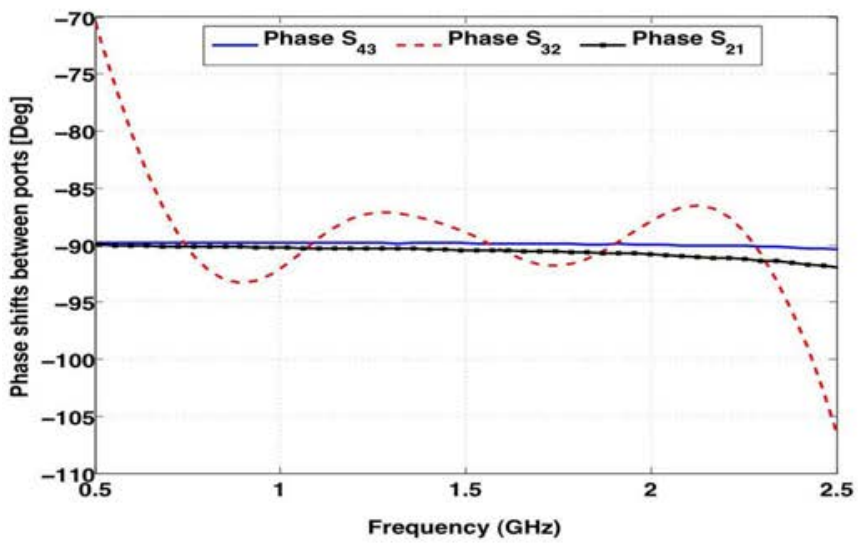

(c)

Fig. 6. Measurement: (a) scheme of the feeding circuitry, (b) amplitude in decibels of the scattering parameters, and (c) phase shifts in degree between ports.

\section{Far-Field Measurement}

The antenna has been measured with the four ports fed simultaneously. This configuration is illustrated in Fig. 5. The antenna

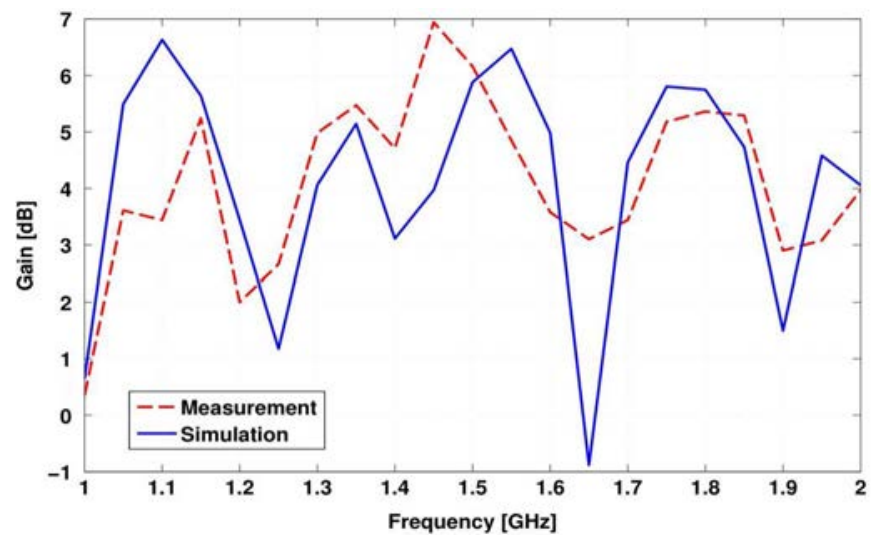

Fig. 7. Measurement: comparison of the measured and simulated gain of the $4 \times 2$-arms spiral antenna.
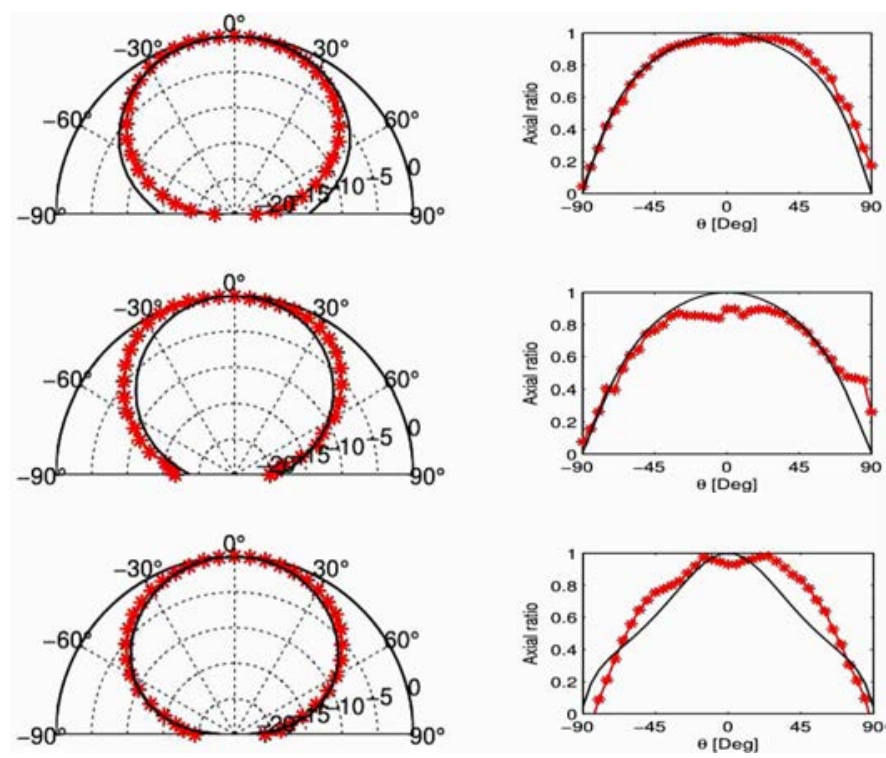

Fig. 8. Measurement: comparison of the measured (cross) and simulated (black solid line) cuts in elevation of the (left) normalized gain and (right) AR at (top) 1.4 , (middle) 1.5 , and (bottom) $1.8 \mathrm{GHz}$.

is positioned at $3 \mathrm{~cm}$ above a ground plane. All the circuitry for the feeding is placed behind this plane, which decreases its effect on the antenna behavior. In order to achieve the correct set of phases, two $90^{\circ}$ and one $180^{\circ}$ phase shifter have been used.

A scheme of the phase shifters is presented in Fig. 6(a). The corresponding measured scattering parameters are plotted in Fig. 6(b) and (c).

From this figure, it can be seen that both an amplitude error and a phase error are introduced by the feeding circuitry. The amplitude is not equal at each port over the entire measured bandwidth, and the phase shift between two consecutive ports is not constant and equal to $90^{\circ}$. These errors influence the measurement results, especially the AR presented in Fig. 8, where the value is not equal to 1 (theoretical value, as in Fig. 3) at boresight.

Measured and simulated gain are plotted in Fig. 7. The variations of the two curves are similar except at $1.65 \mathrm{GHz}$. Within the frequency band of interest, the measured gain varies from 3 to $7 \mathrm{~dB}$, with a maximum at the frequency $1.45 \mathrm{GHz}$. According 
to Fig. 2, the variation of the gain is in good correlation with the $\mathrm{ARC}$ of the antenna. Indeed, the maximum value at $1.45 \mathrm{GHz}$ corresponds to an $\mathrm{ARC} \leq-20 \mathrm{~dB}$, while the minimum gain at $1 \mathrm{GHz}$ is related to an ARC close to $-3 \mathrm{~dB}$.

The measurement results of this configuration are given in Fig. 8. A cut in elevation of the normalized gain with the AR is plotted at three frequencies. Good agreement is shown between simulation and measurement results. Due to the ground plane, the antenna radiates in only one direction, which is illustrated by the polar plot of the gain. According to the AR, the polarization radiated is right-hand circular over $\pm 50^{\circ}$ at boresight, which is wider than the case without the ground plane.

\section{CONCLUSION}

In this letter, a new externally fed spiral antenna has been presented. The $4 \times 2$-arms spiral antenna is a slot antenna matched to $50 \Omega$. The design is fed by four unbalanced sources on the plane of the antenna. The measured antenna bandwidth starts from 1.25 to $2 \mathrm{GHz}$ (except between 1.9 and $1.94 \mathrm{GHz}$, where $\mathrm{ARC} \leq-9.2 \mathrm{~dB}$ ) and could be improved by optimizing the center of the antenna and the matching transition. Over this frequency band, the gain of the $4 \times 2$-arms spiral antenna is above $3 \mathrm{~dB}$ (with gound plane), and a good circular polarization is radiated within an angular range of $\pm 30^{\circ}\left( \pm 50^{\circ}\right.$ in a ground plane configuration). Moreover, the antenna could radiate four different polarizations (linear vertical/horizontal and circular right/left) following the amplitudes and phase shifts applied to the ports. The antenna has been measured by feeding simultaneously all the ports. Measurement results have confirmed the expectations, and a good agreement with simulation has been observed.

\section{REFERENCES}

[1] J. D. Kraus and R. J. Marhefka, Antennas for All Applications, 3rd ed. New York: McGraw-Hill, 2002.

[2] R. G. Corzine and J. A. Mosko, Four-Arm Spiral Antennas, 1st ed. Norwood, MA: Artech House, 1990.

[3] C. W. Jung, B. A. Cetiner, and F. De Flavis, "A single-arm circular spiral antenna with inner/outer feed circuitry for changing polarization and beam characteristics," in Proc. IEEE Antennas Propag. Soc. Int. Symp., Jun. 2003, vol. 4, pp. 474-477.

[4] D. J. Muller and K. Sarabandi, "Design and analysis of a 3-arm spiral antenna," IEEE Trans. Antennas Propag., vol. 55, no. 2, pp. 258-266, Feb. 2007.

[5] E. Gschwendtner and W. Wiesbeck, "Ultra-broadband car antennas for communications and navigation applications," IEEE Trans. Antennas Propag., vol. 51, no. 8, pp. 2020-2027, Aug. 2003.

[6] K. Louertani, N. Ribière-Tharaud, R. Guinvarc'h, and M. Hélier, "Coplanar feeding solution for spiral antenna," in Proc. IEEE APSURSI, Jun. 1-5, 2009, pp. 1-4.

[7] K. Louertani, R. Guinvarch, N. Ribière-Tharaud, and M. Hélier, "External and coplanar feeding for spiral antenna," in Proc. IEEE APSURSI, 2010, pp. 1-4.

[8] K. Louertani, R. Guinvarc'h, N. Ribière-Tharaud, and M. Hélier, "Study of the radiated polarization of an antenna array with circular geometry," Prog. Electromagn. Res. C, vol. 24, pp. 173-183, 2011

[9] R. Guinvarc'h and R. L. Haupt, "Dual polarization interleaved spiral antenna phased array with an octave bandwidth," IEEE Trans. Antennas Propag., vol. 58, no. 2, pp. 397-403, Feb. 2010.

[10] FEKO. EM Software \& Systems-S.A., Stellenbosch, South Africa, 2004. 